\title{
Food consumption in Mexican adolescents
}

\author{
Luis Ortiz-Hernández and Blanca Lilia Gómez-Tello
}

Suggested citation Ortiz-Hernández L, Gómez-Tello BL. Food consumption in Mexican adolescents. Rev Panam Salud Publica. 2008;24(2):127-35.

\begin{abstract}
Objective. To examine the relationship between demographic and socioeconomic factors and food consumption in Mexican adolescents.

Methods. A representative sample $(\mathrm{n}=7$ 218) of Mexican adolescents (12-19 years old) was analyzed. Independent variables included age, gender, and main activity of the adolescents; gender and age of the head of household; socioeconomic position; size of town (rural, semiurban, or urban); and area of residence. The consumption frequency of 13 food groups was assessed. Through multivariate logistic regression models, the effect of independent variables over consumption frequency was evaluated.

Results. Among Mexican adolescents only one-third consumed fruits and vegetables daily, a little less than one-half consumed dairy products daily, one-third drank soft drinks daily, and one-fifth consumed sweets and salty snacks. Males reported higher consumption of legumes. Age increase was associated with higher frequency of milk consumption. Adolescents who worked and those who neither studied nor worked consumed fruits, sweets, and salty snacks less frequently. Eating fruits, vegetables, cereals, dairy products, bread, starchy vegetables, red meat, white meat, and fast food decreased with regard to socioeconomic position; on the other hand, the lower socioeconomic strata had more frequent consumption of legumes and soft drinks.

Conclusions. There are groups of adolescents who are less likely to consume healthy foods (such as fruits, vegetables, and dairy products). Socioeconomic and cultural processes that can explain the differences observed are discussed.
\end{abstract}

Key words Diet, adolescents, socioeconomic status, gender, Mexico.

Obesity in Mexico has been considered a public health problem, as it affects a large number of people. In the year 2000, among Mexican adolescents aged 10-17 years, the prevalence of overweight was $24.7 \%$ (1). For the year 2006 (2), the prevalence of overweight

Health Care Department, Metropolitan Autonomous University-Xochimilco, Mexico City, Mexico. Send correspondence to: Luis Ortiz-Hernández (UAM-X), Calzada del Hueso 1100, Col. Villa Quietud, Coyoacán, 04960 México, D.F., México; phone: (+52) (55) 5483-7573; fax: (+52) (55) 5483-7218; e-mail: lortiz@correo.xoc.uam.mx. and obesity in males 12-19 years of age was $31.2 \%$, while in females it was $32.5 \%$. Similar to some other chronic illnesses, obesity is related to eating habits and consumption of energy and macronutrients. In Mexico, during recent decades, there has been an increase in morbidity and mortality due to diet-associated diseases, such as obesity, high blood pressure, diabetes mellitus, and coronary cardiopathy (3).

In 2005, 20.4\% of Mexicans were between 12 and 19 years of age (4). Characterizing eating habits in adolescents is important because dietary habits initiated at these ages have a higher probability of persisting during adult life (5). Additionally, obese adolescents have a higher risk of morbidity in adulthood due to coronary cardiopathy, arteriosclerosis, and gout (6).

With the exception of reproductive health-related topics, other aspects associated with the health and nutritional conditions of adolescents have been a matter of less interest. In contrast, the nutritional status and diet of other age groups, such as preschool 
and adult populations, have been studied more. This situation probably results from adolescents having low mortality due to infectious and chronic diseases (5).

Nutritional problems frequently observed in adolescents from industrialized countries comprise the following: low consumption of fruits and vegetables; frequent consumption of foods with high energy density; and deficiencies of certain micronutrients such as zinc, calcium, iron, and vitamin $\mathrm{A}$ $(5,7)$. However, few studies have been conducted (8-10) that describe the food consumption of adolescents from middle- and low-income countries.

In industrialized nations, persons of lower socioeconomic position have less healthy diets than individuals with higher socioeconomic position (11); nonetheless, there is evidence (10) that these findings could not be extrapolated to middle- or low-income countries. Additionally, there are few studies in adolescents on the role of certain demographic characteristics in food consumption, such as occupational activity or the size of the town where they live. The aim of this research was to examine the association of socioeconomic and demographic factors with food consumption in adolescents from Mexico.

\section{MATERIALS AND METHODS}

The 2005 National Youth Survey (NYS05) database was analyzed (12). The sample design was probabilistic, stratified, and multistage. For sampling, Mexico was divided into five geographic regions (described later). In each region, census tracts were selected in proportion to the number of inhabitants. Sampling stages included census tracts, blocks, households, and subjects. In households, one subject aged 12-29 years was selected; if there were two or more eligible respondents in the household, the subject whose birth date was nearer in time was chosen to interview. After data were edited, the sample $(n)$ included 7218 cases that represented the entire adolescent 12- to 19-year-old popula- tion of Mexico. Using the sampling weights, these data correspond to an estimated total population $(N)$ size of 16384551 adolescents. The nonresponse rate was $15 \%$, and the error margin was $1.8 \%$. Information was gathered by means of a questionnaire applied at face-to-face interviews. Participant adolescents gave verbal consent, and they were isolated from their families to ensure confidentiality and thus improve the quality of the data.

The following demographic characteristics were analyzed: age of the adolescents (12-14, 15-17, and 18-19 years), main activity of the adolescents (only studying, only working, studying and working, and neither studying nor working), and gender and age of the head of household $(\leq 29,30-39$, $40-49,50-59$, and $\geq 59$ years).

Socioeconomic position was evaluated through two indicators: education of the head of household (as defined by the interviewee) and household assets. Four categories were used with respect to education: very low (primary school or less), low (secondary school or secretarial career), middle (high school, technical career, or teacher training), and high (bachelor's degree or more). Assets found less frequently in Mexican households were selected to estimate an index based on household possessions (4): washing machine, refrigerator, telephone, car or van, computer, and heater or gas boiler. The number of assets in each household were added, and four strata were formed: very low (two or fewer assets); low (three or four assets); medium (five assets), and high (six assets).

Town size was divided into three categories: rural ( $\leq 2499$ inhabitants), semiurban (2 500-19 999 inhabitants), and urban ( $\geq 20000$ inhabitants). The 32 Mexican states were divided into five regions or area of residence: Northwest, Northeast, Central-West, Central, and South.

The frequency of intake of 13 food groups was assessed: fruits, vegetables, cereals (wheat and oats), starchy vegetables (potatoes and sweet potatoes), legumes (beans, broad beans, and lentils), dairy products, red meat (beef and pork), white meat (chicken and fish), soft drinks, sweets, salty snacks, fast food (hot dogs, sandwiches, and tortas), and bread. Response options were the following: never, every now and then, at sometime during the week, and daily. All the response options were dichotomized. For fruits, vegetables, cereals, dairy products, bread, soft drinks, sweets, and salty snacks, the following groups were formed: (1) daily consumption, and (2) consumption at sometime during the week, every now and then, and never. For starchy vegetables, legumes, red meat, white meat, and fast food, the groups were (1) daily consumption and at sometime during the week, and (2) consumption every now and then and never.

For statistical analysis, sample weights considering sample poststratification were used, because they allowed the sample's gender and age distribution to better approximate that registered by the 2000 General Population and Housing Census. Analysis was done with SAS software, which allows taking into account NYS05's complex design. Absolute and relative frequencies of variables were obtained. Later, multivariate logistic regression models were estimated, in which the dependent variables were food consumption and the independent variables comprised age, gender, and main activity of the adolescents; socioeconomic position, age, and gender of the head of household; size of town; and area of residence. As a first step, all independent variables in each model were included and were progressively dismissed if their association with food consumption was not statistically significant $(P>0.050)$. From logistic regression models, odds ratios (ORs) were estimated with their corresponding 95\% confidence intervals (95\% CI).

\section{RESULTS}

In Table 1, descriptive characteristics of the population are shown. There was nearly the same proportion of females and males; most adolescents were between 12 and 14 years old, and adolescents who only studied predom- 
TABLE 1. Sample descriptive characteristics of Mexican adolescents, 2005

\begin{tabular}{|c|c|c|}
\hline & No. & $\%$ \\
\hline \multicolumn{3}{|l|}{ Sex } \\
\hline Male & 3471 & 49.2 \\
\hline Female & 3747 & 50.8 \\
\hline \multicolumn{3}{|l|}{ Age (years) } \\
\hline $12-14$ & 2793 & 38.3 \\
\hline $15-17$ & 2653 & 35.5 \\
\hline $18-19$ & 1772 & 26.2 \\
\hline \multicolumn{3}{|l|}{ Main activity } \\
\hline Study & 5511 & 73.2 \\
\hline Work & 543 & 9.8 \\
\hline Study and work & 250 & 4.8 \\
\hline Neither study nor work & 914 & 12.2 \\
\hline \multicolumn{3}{|l|}{ SEP, ${ }^{a}$ education } \\
\hline Very low & 3002 & 45.4 \\
\hline Low & 1907 & 24.3 \\
\hline Medium & 1533 & 20.0 \\
\hline High & 702 & 10.3 \\
\hline \multicolumn{3}{|l|}{ SEP, assets } \\
\hline Very low & 2079 & 33.2 \\
\hline Low & 2636 & 31.9 \\
\hline Medium & 1309 & 16.6 \\
\hline High & 1194 & 18.3 \\
\hline \multicolumn{3}{|l|}{ Sex of family's head } \\
\hline Male & 6066 & 82.4 \\
\hline Female & 1152 & 17.6 \\
\hline \multicolumn{3}{|l|}{ Age of family's head (years) } \\
\hline 29 or less & 297 & 5.8 \\
\hline $30-39$ & 2279 & 29.4 \\
\hline $40-49$ & 2825 & 39.4 \\
\hline $50-59$ & 1108 & 15.7 \\
\hline$\geq 60$ & 691 & 9.7 \\
\hline \multicolumn{3}{|l|}{ Size of town } \\
\hline Rural & 547 & 0.5 \\
\hline Semiurban & 1669 & 12.5 \\
\hline Urban & 5002 & 87.0 \\
\hline \multicolumn{3}{|l|}{ Region } \\
\hline Central & 1178 & 31.0 \\
\hline Northeast & 1614 & 12.8 \\
\hline Northwest & 384 & 7.4 \\
\hline Central-West & 2679 & 24.4 \\
\hline South & 1363 & 24.4 \\
\hline
\end{tabular}

inated. With both education and assets, the low and very low socioeconomic statuses predominated. For head of household, $17.6 \%$ were females and $39.4 \%$ were $40-49$ years of age.

Frequency of food consumption of adolescents is presented in Table 2 . Foods such as dairy products, bread, legumes, fruit, vegetables, and soft drinks were consumed most frequently, while foods consumed least frequently were fast food, red meat, and starchy vegetables.

TABLE 2. Food consumption frequency of Mexican adolescents, 2005

\begin{tabular}{lccccc}
\hline & No. & $\begin{array}{c}\mathrm{N}^{\mathrm{a}} \\
(\%)\end{array}$ & $\begin{array}{c}\mathrm{ENT}^{\mathrm{b}} \\
(\%)\end{array}$ & $\begin{array}{c}\mathrm{SW}^{\mathrm{c}} \\
(\%)\end{array}$ & $\begin{array}{c}\mathrm{ED}^{\mathrm{d}} \\
(\%)\end{array}$ \\
\hline Fruits & 7203 & 1.1 & 19.3 & 40.5 & 39.1 \\
Vegetables & 7208 & 2.8 & 17.5 & 43.3 & 36.4 \\
Cereals & 7200 & 7.8 & 25.8 & 39.6 & 26.8 \\
Starchy vegetables & 7200 & 3.6 & 32.1 & 45.9 & 18.4 \\
Dairy products & 7203 & 1.9 & 15.4 & 33.8 & 48.9 \\
Legumes & 7204 & 0.8 & 19.8 & 38.4 & 41.0 \\
Red meat & 7207 & 1.4 & 29.8 & 56.3 & 12.5 \\
White meat & 7205 & 0.8 & 29.9 & 54.0 & 15.3 \\
Soft drinks & 7205 & 4.1 & 28.3 & 34.5 & 33.1 \\
Sweets & 7203 & 6.0 & 32.8 & 34.7 & 26.5 \\
Salty snacks & 7205 & 7.1 & 35.6 & 33.5 & 23.8 \\
Fast food & 7193 & 12.3 & 43.7 & 32.7 & 11.3 \\
Bread & 6974 & 1.1 & 19.9 & 35.8 & 43.2 \\
\hline
\end{tabular}

a $=$ never.

${ }^{b}$ ENT = every now and then.

c SW = sometime during the week.

${ }^{\mathrm{d}} \mathrm{ED}=$ every day.

Multivariate logistic regressionmodel results are presented in Tables 3 to 5 , with consumption of food groups as the dependent variable. Fruit consumption was higher in adolescents living in households headed by older persons but was lower in those who both studied and worked; who neither studied nor worked; who belonged to the low and very low education status; and who lived in Northeastern, Northwestern, and Southern Mexico. Vegetable consumption was lower in adolescents who neither studied nor worked, who had low socioeconomic position (according to education or household assets), and who lived in the Northwest and South. Frequency of cereal consumption was lower in adolescents who worked, in those who neither studied nor worked, in those with low socioeconomic status (defined by the two socioeconomic position indicators), and in those who lived in Northwestern Mexico. Dairy products were less frequently consumed by adolescents who worked; those who neither studied nor worked; those with low socioeconomic position; those who lived in Northeastern, Northwestern, and Southern Mexico; and those who lived in households headed by males.

Bread consumption was less frequent in adolescents with low socio- economic position and in those who lived in Northeastern, Northwestern, Central-Western, and Southern regions. There was a higher frequency of starchy vegetable consumption in individuals residing in semiurban localities; on the other hand, there was less consumption of this food by individuals who worked, who had low socioeconomic status (defined by household assets), and who resided in households in which the head was older. Adolescents with low socioeconomic position (defined by education and household assets) and those who resided in rural areas consumed less red meat. White meat consumption was lower in subjects living in rural areas, in those who neither studied nor worked, and in those with very low socioeconomic status (defined by household assets).

Soft drinks were less frequently consumed by those residing in households headed by a male and in rural areas; in contrast, soft drink intake was higher in those with low socioeconomic status. Adolescents with low socioeconomic position consumed less fast food, whereas those living in Northeastern and Central-Western Mexico consumed more of these foods. Consumption of sweets was lower in adolescents who worked and studied, in those who neither studied nor 
TABLE 3. Regression models having as dependent variables Mexican adolescents' consumption of fruits, vegetables, cereals, and dairy products, 2005

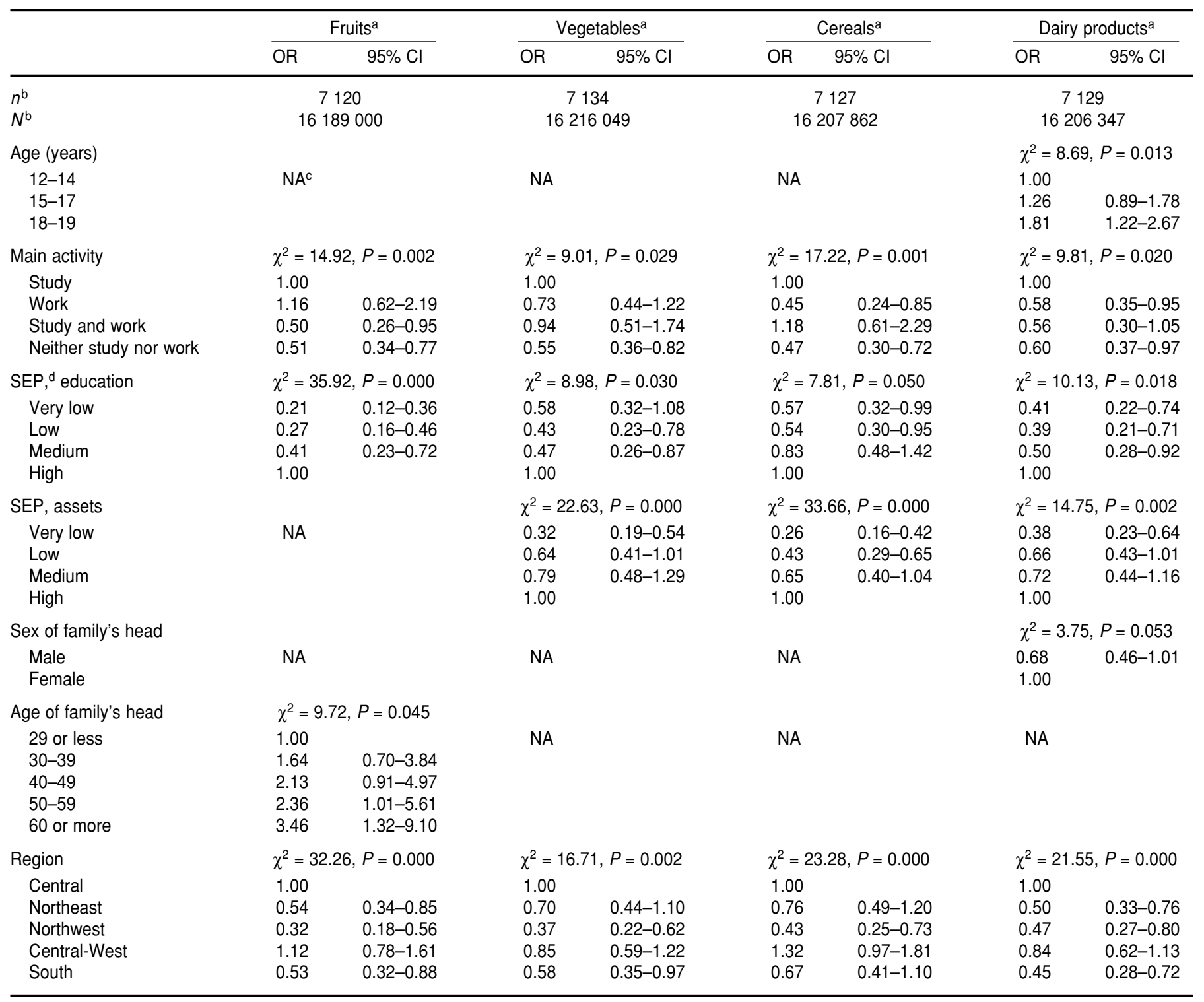

a The "every day" consumption frequency was modeled.

${ }^{b}$ The sample sizes are different because of differences in amount of complete (or missing) data for different combinations of variables.

${ }^{\mathrm{C}} \mathrm{NA}=$ not available because variables were not statistically significant in regression models.

${ }^{d}$ SEP $=$ socioeconomic position.

worked, in those who lived in households headed by a male, and in adolescents living in rural areas. Salty snacks were less frequently consumed by adolescents who worked, who neither studied nor worked, who lived in households headed by a male, and who lived in rural areas.

Consumption of legumes ( $n=7204$, $N=16374443$ ) was higher in males
$\left(\mathrm{OR}=1.66,95 \% \mathrm{CI}=1.09-2.51, \chi^{2}=\right.$ 5.62, $P=0.018$ ) and in individuals with low socioeconomic status as defined by education $\left(\chi^{2}=15.30\right.$, $P=0.002$; middle socioeconomic status: $\mathrm{OR}=2.91,95 \% \mathrm{CI}=1.58-5.34$; low status: $\mathrm{OR}=2.40,95 \% \mathrm{CI}=$ 1.41-4.10; very low status: $\mathrm{OR}=2.28$, $95 \% \mathrm{CI}=1.27-4.10$ ) (results not shown in tables).

\section{DISCUSSION}

Considering dietary recommendations (13), the following findings are worrisome: among Mexican adolescents only one-third consumed fruits and vegetables daily, a little less than one-half consumed dairy products daily, one-third drank soft drinks daily, and one-fifth of Mexican adoles- 
TABLE 4. Regression models having as dependent variables Mexican adolescents' consumption of bread, starchy vegetables, red meat, and white meat, 2005

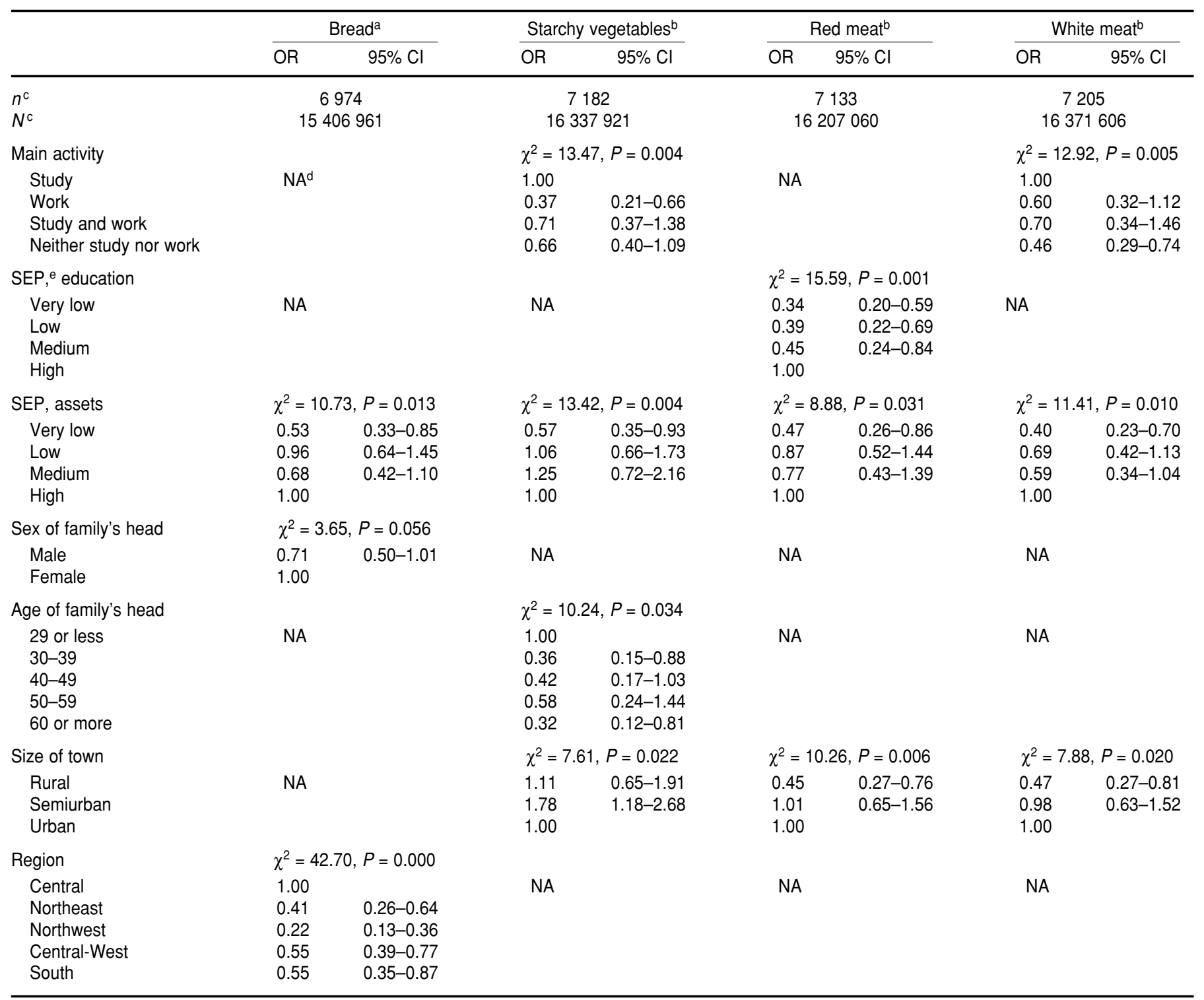

a The "every day" consumption frequency was modeled.

b The "sometime during the week" and "every day" consumption frequency were modeled.

${ }^{c}$ The sample sizes are different because of differences in amount of complete (or missing) data for different combinations of variables.

${ }^{\mathrm{d}} \mathrm{NA}=$ not available because variables were not statistically significant in regression models.

${ }^{e}$ SEP = socioeconomic position.

cents consumed sweets and salty snacks. Low consumption of fruits and vegetables has also been observed in adolescents in Belgium (14), Costa Rica (8), Spain (15-17), England (18, 19), and Scotland (20).

Although differences by gender have been reported for consumption of fruits, vegetables, dairy products, and red meat (21), in Mexican adolescents the only difference was found with respect to legumes: males exhibited a higher consumption. In Costa Rican adolescents, the same trend was observed (8), while in adolescents from Scotland there were no differences (22). NYS05 analysis showed that increased age was associated with more frequent consumption of dairy products. Foodassociated meanings could explain these patterns: increased age and the adoption of certain social roles (i.e., marriage) coincide with increased consumption of foods that are symbolically related to adulthood (i.e., dairy products) (23).

In Mexico, adolescents who studied and worked and those who neither studied nor worked consumed fruits, sweets, and salty snacks less fre- 
Table 5. Regression models having as dependent variables Mexican adolescents' consumption of soft drinks, fast food, sweets, and salty snacks, 2005

\begin{tabular}{|c|c|c|c|c|c|c|c|c|}
\hline & \multicolumn{2}{|c|}{ Soft drinks ${ }^{a}$} & \multicolumn{2}{|c|}{ Fast food ${ }^{b}$} & \multicolumn{2}{|c|}{ Sweets $^{a}$} & \multicolumn{2}{|c|}{ Salty snacks ${ }^{a}$} \\
\hline & OR & $95 \% \mathrm{Cl}$ & OR & $95 \% \mathrm{Cl}$ & OR & $95 \% \mathrm{Cl}$ & OR & $95 \% \mathrm{Cl}$ \\
\hline $\begin{array}{l}n^{\mathrm{c}} \\
N^{\mathrm{c}}\end{array}$ & \multicolumn{2}{|c|}{7205} & \multicolumn{2}{|c|}{7119} & \multicolumn{2}{|c|}{7203} & \multicolumn{2}{|c|}{7205} \\
\hline Main activity & & & & & \multicolumn{2}{|c|}{$\chi^{2}=16.12, P=0.001$} & \multicolumn{2}{|c|}{$\chi^{2}=12.23, P=0.007$} \\
\hline $\begin{array}{l}\text { Study } \\
\text { Work } \\
\text { Study and work } \\
\text { Neither study nor work }\end{array}$ & \multicolumn{2}{|c|}{$N A^{d}$} & \multicolumn{2}{|l|}{ NA } & $\begin{array}{l}1.00 \\
0.54 \\
0.44 \\
0.50\end{array}$ & $\begin{array}{l}0.28-1.02 \\
0.22-0.85 \\
0.32-0.78\end{array}$ & $\begin{array}{l}1.00 \\
0.50 \\
0.40 \\
0.61\end{array}$ & $\begin{array}{l}0.26-1.00 \\
0.19-0.84 \\
0.39-0.96\end{array}$ \\
\hline SEP, education & & & \multicolumn{2}{|c|}{$\chi^{2}=13.03, P=0.005$} & & & & \\
\hline $\begin{array}{l}\text { Very low } \\
\text { Low } \\
\text { Medium } \\
\text { High }\end{array}$ & \multicolumn{2}{|l|}{ NA } & $\begin{array}{l}0.65 \\
0.67 \\
1.43 \\
1.00\end{array}$ & $\begin{array}{l}0.36-1.16 \\
0.38-1.21 \\
0.77-2.65\end{array}$ & \multicolumn{2}{|l|}{ NA } & \multicolumn{2}{|l|}{ NA } \\
\hline Sex of family's head & \multicolumn{4}{|c|}{$\chi^{2}=10.21, P=0.001$} & \multicolumn{2}{|c|}{$\chi^{2}=5.29, P=0.022$} & \multicolumn{2}{|c|}{$\chi^{2}=4.21, P=0.040$} \\
\hline $\begin{array}{l}\text { Male } \\
\text { Female }\end{array}$ & $\begin{array}{l}0.53 \\
1.00\end{array}$ & $0.36-0.78$ & \multicolumn{2}{|l|}{$\begin{array}{l}\text { NA } \\
1.00\end{array}$} & $\begin{array}{l}0.59 \\
1.00\end{array}$ & $0.38-0.93$ & 0.62 & $0.39-0.98$ \\
\hline Size of town & \multicolumn{4}{|c|}{$\chi^{2}=21.47, p=0.000$} & \multicolumn{2}{|c|}{$\chi^{2}=16.27, P=0.000$} & \multicolumn{2}{|c|}{$\chi^{2}=14.40, P=0.001$} \\
\hline $\begin{array}{l}\text { Rural } \\
\text { Semiurban } \\
\text { Urban }\end{array}$ & $\begin{array}{l}0.31 \\
0.62 \\
1.00\end{array}$ & $\begin{array}{l}0.18-0.52 \\
0.42-0.91\end{array}$ & \multicolumn{2}{|l|}{ NA } & $\begin{array}{l}0.35 \\
0.88 \\
1.00\end{array}$ & $\begin{array}{l}0.21-0.58 \\
0.58-1.35\end{array}$ & $\begin{array}{l}0.31 \\
1.00 \\
1.00\end{array}$ & $\begin{array}{l}0.17-0.57 \\
0.65-1.51\end{array}$ \\
\hline Region & & & \multicolumn{2}{|c|}{$\chi^{2}=12.54, P=0.014$} & & & & \\
\hline $\begin{array}{l}\text { Central } \\
\text { Northeast } \\
\text { Northwest } \\
\text { Central-West } \\
\text { South }\end{array}$ & \multicolumn{2}{|l|}{ NA } & $\begin{array}{l}1.00 \\
2.01 \\
1.27 \\
1.44 \\
1.17\end{array}$ & $\begin{array}{l}1.32-3.06 \\
0.80-2.03 \\
1.07-1.92 \\
0.75-1.84\end{array}$ & \multicolumn{2}{|l|}{ NA } & \multicolumn{2}{|l|}{ NA } \\
\hline
\end{tabular}

a The "every day" consumption frequency was modeled.

b The "sometime during the week" and "every day" consumption frequencies were modeled.

c The sample sizes are different because of differences in amount of complete (or missing) data for different combinations of variables.

d NA, not available because variables were not statistically significant in regression models.

e SEP = socioeconomic position.

quently; those who neither studied nor worked consumed vegetables, cereals, dairy products, and white meat less frequently. Adolescents who worked ate cereal, dairy products, and starchy vegetables less frequently. Similar patterns were observed in Irish adolescents (22). These results could indicate that entering the labor market is related to the adoption of unhealthy eating habits, which could result from these adolescents having their own income, which allows them to consume meals prepared outside the home, which tend to have fewer nutrients and higher energy density $(24,25)$.

In Mexico, increased age of the head of household was positively related to adolescent fruit consumption as well as to lower consumption of starchy vegetables. It is possible that as heads of household advance in age, they develop more child-rearing skills and are more concerned about healthy behaviors; thus, they tend to provide more food in the home that is perceived to be healthy. With regard to the latter, among Australian adults (26), those aged between 35 and 49 years consumed more fruits, vegetables, and fish but fewer cereals, dairy products, meat, snacks, and sweets than the 18to 34-year age group.

Considering that women more commonly adopt health-associated behaviors $(16,18,27,28)$, we expected that adolescents from households headed by females would have higher consumption of foods such as fruits, vegetables, and milk and lower consumption of foods with high energy density. The lower consumption of dairy prod- 
ucts observed in Mexican adolescents living in households headed by males supports this idea; nonetheless, these adolescents also consumed bread, soft drinks, sweets, and salty snacks less frequently. A possible reason for this finding is that, in households headed by males, it is more likely that a woman (i.e., the wife) plans, purchases, and prepares family meals. On the other hand, when a female is the head of household, she is usually a single mother holding a salaried job, which limits her time for planning, buying, and preparing meals. Thus, female heads of household tend to purchase convenient and industrially processed food items.

In Mexican adolescents, consumption of fruits, vegetables, cereals, dairy products, starchy vegetables, bread, red meat, white meat, and fast food diminished with decreasing socioeconomic position; conversely, individuals in a low social position consumed legumes and soft drinks more frequently. In industrialized countries, adolescents with low social status had lower consumption of fruits $(29,30)$, vegetables $(15,31-34)$, cheese $(34,35)$, and milk $(30,34)$. It has been observed that Australian adults with low socioeconomic position consumed more legumes (26). In adolescents in Northern, Southern, and Western European countries $(15,29)$, soft-drink consumption was negatively related to socioeconomic position; the opposite was observed in Central and Eastern European countries (29). There is no consistent pattern for the remaining foods. In Spanish adolescents, consumption of salty snacks was negatively related to socioeconomic position (15), whereas in Swedish adolescents it was not related to fast food consumption (34); however, in Swedish female adolescents-but not in males-a socioeconomic index of residence areas was negatively related to meat, fish, and egg intake (34). In Finnish children and adolescents, there were no socioeconomic differences in consumption of meat and meat products (30). In adolescents from two Chinese provinces, consumption of fruits, juices, milk, yogurt, and soft drinks was lower in the low socioeconomic group, although rice intake was higher; in addition, males with high socioeconomic position had higher consumption of shrimp, pork, hamburgers, and chocolate (10). In Costa Rican adolescents, the parents' educational level was positively related to fruit and vegetable intake (9).

Socioeconomic differences regarding food consumption observed among Mexican adolescents could be partially attributed to food prices in the country: the least expensive products comprise sugar, oils, and cereals, followed by meat and canned fish, dairy products, vegetables, and fruits; the most expensive product is fresh seafood (36). Although in Mexico the prices of beef and chicken, industrialized food (which includes snacks), and food prepared outside the home have decreased over the past years, these products remain more expensive than others such as sugar and legumes. Moreover, during the past decade the price of basic cereals, such as corn, has increased (36).

With NYS05 data, it was observed that the two indicators for socioeconomic position were independently associated with consumption of certain foods. In multivariate models, the head of household's education and the indicator based on household assets were positively associated with consumption of vegetables, cereals, dairy products, red meat, and fast food. This result supports the notion that each socioeconomic position indicator measures a different dimension of social stratification (37); therefore, they can be independently related to health behaviors. Education is the cultural dimension indicator of socioeconomic stratification, while the household assets indicator reflects the wealth of the household. The head of household's education was negatively related to consumption of legumes; additionally, soft drink consumption was higher in the low and medium strata, as defined by the household-assets indicator, but it was lower in the high and very low socioeconomic strata. This pattern cannot be explained by food prices, because legumes are inexpensive and therefore are accessible to individuals in the higher strata, while soft drinks in Mexico remain more expensive than other food types (36). Bourdieu (27) stated that starchy foods (such as cereals and legumes) and those with high energy density are preferred by persons with low socioeconomic position because these foods have been symbolically associated with qualities such as physical strength.

Compared with Mexican adolescents residing in urban localities, those living in rural areas consumed red meat, white meat, soft drinks, sweets, and salty snacks less frequently; adolescents from semiurban localities consumed starchy vegetables more frequently but fewer soft drinks. These differences can be attributed to the fact that urbanization leads to a greater availability of food, especially industrially processed food products. In Chinese male adolescents, those residing in urban areas exhibited a higher intake of fruits, juice, milk, and yogurt; in Chinese female adolescents, differences were also observed in fruit and milk consumption, but the opposite pattern was observed for rice consumption in both genders and for vegetables in males (10). In Costa Rican adolescents, those living in urban areas had a higher intake of vegetables but a lower intake of fruits (8). In highincome countries, no clear patterns have been observed with respect to food consumption when comparing urban and rural localities $(15,34)$.

Compared with adolescents in Central Mexico, those residing in Northeastern and Central-Western Mexico consumed fast food more frequently. These regions are characterized as having greater economic development and more livestock; additionally, because of their geographic proximity to the United States, it may be implied that these are the first regions where fast food restaurants appeared. On the other hand, adolescents in Central Mexico tended to consume more fruits, vegetables, dairy products, cereals, and bread. Mexico City is included in this region, where one-fifth of the Mexican population lives and where the country's most important food distribution centers are located. 
In Mexico, one-third of adolescents are overweight or obese (2); the regions with the highest rates are the North (29.4\% in males and $31.1 \%$ in females) and Mexico City $(28.5 \%$ and $31.6 \%$, respectively); in contrast, the South ( $20.0 \%$ and $24.9 \%$, respectively) has the lowest prevalence of overweight and obesity. Our findings show that the frequency and distribution of consumption of food with high energy density are similar to the rates of overweight and obesity; the proportion of adolescents who daily ingested soft drinks, sweets, and salty snacks are $33.1 \%$, $26.5 \%$, and $23.8 \%$, respectively. Coincidentally, the North region is where more adolescents eat fast food. This situation must translate in the design and execution of nutrition education programs focused on reducing the intake of food with high energy density, especially in the North and Mexico City.

One limitation of this research comprises the dietary assessment instrument. This is due to the following: (1) The investigated food groups in the questionnaire were general; thus, a more detailed analysis concerning specific foods was not possible. (2) It would be helpful to evaluate separately certain food items included in the same groups (i.e., fish and chicken), because their consumption might not be related. (3) The consumption of some important foods in the Mexican diet was not assessed, such as eggs, tortillas, and Mexican dishes. (4) Certain consumption-frequency options are ambiguous (i.e., "every now and then," and "sometime during the week") and do not permit evaluating the number of servings consumed. Although the questionnaire did not allow us to know food consumption in grams, it did allow us to identify differences in consumption levels. In addition, a strength of the investigation lies in that a probabilistic sample was interviewed, which makes it possible to obtain a general view of dietary habits in Mexican adolescents.

The analysis allowed us to identify groups of adolescents with problematic food consumption: the youngest adolescents consumed milk less frequently; those who studied and worked and those who neither studied nor worked consumed fruits less frequently, and the group living in households headed by younger persons consumed less fruit. In addition, those residing in households headed by females consumed more bread, soft drinks, sweets, and salty snacks; adolescents with low socioeconomic position consumed fruits, vegetables, and dairy products less frequently but drank soft drinks more frequently; groups considered in a high socioeconomic position consumed more fast food but consumed legumes less frequently; subjects living in urban areas consumed more soft drinks, sweets, and salty snacks, and those residing in Northeastern and Central-Western Mexico consumed more fast food. Some of the observed results in the Mexican sample are similar to those reported by others, which confers higher validity to the conclusions obtained here. This knowledge can be used to design nutritional education programs. Nevertheless, it should be considered that certain differences in consumption can be the result of socioeconomic or cultural processes, which are difficult to modify. Finally, some of the proposed explanations for understanding the observed differences in food consumption require verification through qualitative research.

Acknowledgments. We are grateful to the Mexican Institute of Youth for allowing access to the Youth National Survey (YNS) 2005 database. This work could not have been conducted without technical information on the YNS graciously provided by Lic. Sofia Serrano-F. (Instituto Mexicano de la Juventud).

\section{REFERENCES}

1. Rio-Navarro BE, Velazquez-Monroy $\mathrm{O}$, Sanchez-Castillo CP, Lara-Esqueda A, Berber A, Fanghanel G, et al. The high prevalence of overweight and obesity in Mexican children. Obes Res. 2004;12:215-23.

2. Olaiz-Fernández G, Rivera-Dommarco J, Shamah-Levy T, Rojas R, VillalpandoHernández S, Hernández-Avila $M$, et al. Encuesta Nacional de Salud y Nutrición 2006. Cuernavaca, México: Instituto Nacional de Salud Pública; 2006.

3. Rivera JA, Barquera S, Campirano F, Campos I, Safdie M, Tovar V. Epidemiological and nutritional transition in Mexico: rapid increase of non-communicable chronic diseases and obesity. Public Health Nutr. 2002;5:113-22.

4. Instituto Nacional de Estadística Geografía e Informática. Conteo de Población y Vivienda 2005. Available from: http://www.inegi.gob. mx. Accessed 10 July 2007.
5. World Health Organization. Nutrition in adolescence-Issues and challenges for the health sector. Issues in Adolescent Health and Development. Geneva: WHO; 2005.

6. Must A, Jacques PF, Dallal GE, Bajema CJ, Dietz WH. Long-term morbidity and mortality of overweight adolescents. N Engl J Med. 1992;327:1350-5.

7. Bull NL. Dietary habits, food-consumption, and nutrient intake during adolescence. J Adolesc Health. 1992;13:384-8.

8. Monge RR. Fruit and vegetable consumption among Costa Rican adolescents. Arch Latinoam Nutr. 2001;51:81-5.

9. Monge RR, Nunez HP, Garita C, Chen-Mok M. Psychosocial aspects of Costa Rican adolescents' eating and physical activity patterns. J Adolesc Health. 2002;31:212-9.

10. Shi Z, Lien N, Kumar BN, Holmboe-Ottesen G. Socio-demographic differences in food habits and preferences of school adolescents in Jiangsu Province, China. Eur J Clin Nutr. 2005;59:1439-48.

11. Drewnowski A, Specter SE. Poverty and obesity: the role of energy density and energy costs. Am J Clin Nutr. 2004;79:6-16.

12. Instituto Mexicano de la Juventud, Secretaría de Educación Pública. Encuesta Nacional de Juventud 2005. Resultados preliminares. México, D.F.: Instituto Mexicano de la Juventud; 2006.

13. U.S. Department of Health and Human Services and U.S. Department of Agriculture. Dietary guidelines for Americans, 2005. 6th edition. Washington, DC: U.S. Government Printing Office; 2005.

14. Paulus D, Saint-Remy A, Jeanjean M. Dietary habits during adolescence-results of the Belgian Adolux Study. Eur J Clin Nutr. 2001;55: 130-6. 
15. Aranceta J, Perez-Rodrigo C, Ribas L, SerraMajem L. Sociodemographic and lifestyle determinants of food patterns in Spanish children and adolescents: the enKid study. Eur J Clin Nutr. 2003;57:S40-4.

16. Perez-Llamas F, Garaulet M, Nieto M, Baraza JC, Zamora S. Estimates of food intake and dietary habits in a random sample of adolescents in south-east Spain. J Hum Nutr Diet. 1996;9:463-71.

17. Watt RG, Sheiham A. Dietary patterns and changes in inner city adolescents. J Hum Nutr Diet. 1996;9:451-61.

18. Hackett AF, Kirby S, Howie M. A national survey of the diet of children aged 13-14 years living in urban areas of the United Kingdom. J Hum Nutr Diet. 1997;10:37-51.

19. Johnson B, Hackett AF. Eating habits of 11- to 14-year-old schoolchildren living in less affluent areas of Liverpool, UK. J Hum Nutr Diet. 1997;10:135-44.

20. Inchley J, Todd J, Bryce C, Currie C. Dietary trends among Scottish schoolchildren in the 1990s. J Hum Nutr Diet. 2001;14:207-16.

21. Jensen KO, Holm L. Preferences, quantities and concerns: socio-cultural perspectives on the gendered consumption of foods. Eur J Clin Nutr. 1999;53:351-9.

22. Sweeting H, Anderson A, West P. Sociodemographic correlates of dietary habits in mid to late adolescence. Eur J Clin Nutr. 1994;48: 736-48.

23. Chapman G, Maclean H. Junk food and healthy food-meanings of food in adolescent women's culture. J Nutr Educ. 1993;25:108-13.
24. Neumark-Sztainer D, Hannan PJ, Story M, Croll J, Perry C. Family meal patterns: associations with sociodemographic characteristics and improved dietary intake among adolescents. J Am Diet Assoc. 2003;103:317-22.

25. Adamson AJ, Rugg-Gunn AJ, Butler TJ, Appleton DR. The contribution of foods from outside the home to the nutrient intake of young adolescents. J Hum Nutr Diet. 1996;9:55-68.

26. Worsley A, Blasche R, Ball K, Crawford D. Income differences in food consumption in the 1995 Australian National Nutrition Survey. Eur J Clin Nutr. 2003;57:1198-211.

27. Bourdieu P. La distincion: criterios y bases sociales del gusto. Madrid: Taurus; 1988

28. Roos E, Lahelma E, Virtanen M, Prattala R, Pietinen P. Gender, socioeconomic status and family status as determinants of food behaviour. Soc Sci Med. 1998;46:1519-29.

29. Vereecken CA, Inchley J, Subramanian SV, Hublet A, Maes L. The relative influence of individual and contextual socio-economic status on consumption of fruit and soft drinks among adolescents in Europe. Eur J Public Health. 2005;15:224-32.

30. Laitinen S, Rasanen L, Viikari J, Akerblom HK. Diet of Finnish children in relation to the family socioeconomic-status. Scand J Soc Med. 1995;23:88-94.

31. Lien N, Jacobs DR, Klepp KI. Exploring predictors of eating behavior among adolescents by gender and socio-economic status. Public Health Nutr. 2002;5:671-81.

32. Giskes K, Turrell G, Patterson C, Newman B. Socio-economic differences in fruit and veg- etable consumption among Australian adolescents and adults. Public Health Nutr. 2002;5: 663-9.

33. Irala-Estevez J, Groth M, Johansson L, Oltersdorf U, Prattala R, Martinez-Gonzalez M. A systematic review of socio-economic differences in food habits in Europe: consumption of fruit and vegetables. Eur J Clin Nutr. 2000; 54:706-14.

34. Hoglund D, Samuelson G, Mark A. Food habits in Swedish adolescents in relation to socioeconomic conditions. Eur J Clin Nutr. 1998;52:784-9.

35. Sanchez-Villegas A, Martinez JA, Prattala R, Toledo E, Roos G, Martinez-Gonzalez MA. A systematic review of socioeconomic differences in food habits in Europe: consumption of cheese and milk. Eur J Clin Nutr. 2003;57: 917-29.

36. Ortiz-Hernandez L. Price evolution of foods and nutriments in Mexico from 1973 to 2004. Arch Latinoam Nutr. 2006;56:201-15.

37. Liberatos P, Link BG, Kelsey JL. The measurement of social-class in epidemiology. Epidemiol Rev. 1988;10:87-121.

Manuscript received on 16 October 2007. Revised version accepted for publication on 19 May 2008.
RESUMEN

Consumo de alimentos en adolescentes mexicanos
Objetivo. Examinar la relación entre algunos factores demográficos y socioeconómicos y el consumo de alimentos en adolescentes mexicanos.

Métodos. Se analizó una muestra representativa $(n=7218)$ de adolescentes mexicanos (de 12-19 años). Como variables independientes se emplearon la edad, el sexo y la actividad principal de los adolescentes; el sexo y la edad del jefe del hogar; la posición socioeconómica; el tamaño de la población de residencia (rural, semiurbana o urbana) y la zona del país. Se determinó la frecuencia del consumo de 13 grupos de alimentos y se evaluó el efecto de las variables independientes sobre la frecuencia de consumo mediante modelos de regresión logística multifactorial.

Resultados. Solo una tercera parte de los adolescentes mexicanos consumía frutas y vegetales diariamente, poco menos de la mitad consumía diariamente productos lácteos, un tercio bebía refrescos todos los días y una quinta parte consumía dulces y golosinas saladas. Los varones presentaron un mayor consumo de legumbres. Una mayor edad se asoció con una mayor frecuencia de consumo de leche. Los adolescentes que trabajaban y los que no trabajaban ni estudiaban consumían frutas, dulces y golosinas saladas con menor frecuencia. El consumo de frutas, vegetales, cereales, productos lácteos, pan, vegetales ricos en almidón, carne roja, carne blanca y comidas instantáneas disminuyó según la posición socioeconómica; además, los grupos de más baja posición socioeconómica consumían legumbres y refrescos con mayor frecuencia.

Conclusiones. Hay grupos de adolescentes menos propensos a consumir alimentos saludables (como frutas, vegetales y productos lácteos). Se discuten las condiciones socioeconómicas y culturales que pueden explicar las diferencias observadas.

Palabras clave Dieta, adolescente, nivel socioeconómico, México. 